\title{
Nicotine Induces the Expression of C-Reactive Protein via MAPK-Dependent Signal Pathway in U937 Macrophages
}

\author{
Junjun Mao ${ }^{1,2}$, Juntian Liu ${ }^{1, *}$, Xiaoming Pang ${ }^{1}$, Ming Li ${ }^{3}$, Jinyan Song ${ }^{1}$, Chunjie Han ${ }^{4}$, Di Wu', and \\ Shuyue Wang ${ }^{1}$
}

\begin{abstract}
Atherosclerosis is an inflammatory disease in the vessel wall. Nicotine, a major component of cigarette smoke, is an independent risk factor for cardiovascular diseases including atherosclerosis. As an inflammatory molecule, C- reactive protein (CRP) participates in atherogenesis. Although it has been confirmed that CRP level in smoking patient is significantly higher than non-smokers and cigarette withdrawal, it is unknown whether nicotine induces CRP expression in macrophages. The present study was to observe effect of nicotine on CRP production and the related signal pathway in U937 macrophages. The results showed that nicotine significantly increased mRNA and protein expression of CRP in U937 macrophages in timeand concentration-dependent ways. Nicotinic acetylcholine receptor (nAChR) blocker hexamethonium, MEK1/2 inhibitor PD98059, p38 MAPK inhibitor SB203580 and NF$\kappa B$ inhibitor PDTC almost completely abolished nicotineinduced CRP expression in mRNA and protein levels in U937 macrophages. The further study indicated that hexamethonium, PD98059, and SB203580 significantly inhibited ERK1/2 and p38 MAPK phosphorylation. These demonstrate that nicotine has ability to induce CRP expression in macrophages through nAChR-ERK1/2/p38 MAPK-NF-кB signal pathway, which contributes to better understanding of the pro-inflammatory and pro-atherosclerotic effects of nicotine in cigarette smokers.
\end{abstract}

\section{INTRODUCTION}

Cigarette smoking has been implicated in numerous diseases including atherosclerosis (Michael, 2000; Tsiara et al., 2003). Nicotine is a predominant chemical in cigarette, and has been suspected to be a causative agent for atherosclerosis. However, the pro-atherogenic mechanism of nicotine is still largely speculative. It is known that nicotine exhibits a direct effect on vessel cells and macrophages. Nicotine stimulates the proliferation and migration of vascular smooth muscle cells (VSMCs), the production of the inflammatory mediators like COX-2, $\mathrm{PGE}_{2}$, TNF- $\alpha, \mathrm{IL}-1 \beta$ and iNOS, and adhesion molecule expression in endothelial cells and macrophages by activating the transcription factor NF-кB (Lau et al., 2006; Wang et al., 2004; Yoshiyama et al., 2011; Zhou et al., 2010). These effects of nicotine are fulfilled mainly through activating nicotinic acetylcholine receptor (nAChR) (Lee and Cooke, 2011).

Macrophages are the predominant nucleated cells differentiated from monocyte in the peritoneal fluid and tissues. It is known that macrophages reside within atherosclerotic plaques (Hansson and Hermansson, 2011), and contribute to the pathology of atherosclerosis. They release various products including pro-inflammatory cytokines that influence other resident cells in tissues (Denis et al., 1991; Haraldsen et al., 1996; Morzycki et al., 1990).

Among the inflammatory cytokines, C- reactive protein (CRP) has been identified as a non-specific but sensitive marker of the acute inflammatory response. CRP is not only an important predictor of cardiocerebrovascular events, but also a direct participator in the formation and development of atherosclerosis (Ridker, 2003). CRP stimulates the proliferation and migration of VSMCs, promotes monocyte aggregation and the complement system activation, and mediates uptake of low density lipoprotein by macrophages to promote the formation of foam cells (Diaz et al., 2003; Zwaka et al., 2001). In addition, CRP modulates the activities and expressions of multiple factors implicated in atherogenesis, such as enhancing IL-8 expression and decreasing endothelial nitric oxide synthase expression and prostacyclin generation in human aortic endothelial cells (Kibayashi et al., 2005; Li et al., 2004; Venugopal et al., 2002; 2003).

Our previous studies indicated that CRP is also expressed in macrophages ( $\mathrm{Li}$ et al., 2011). Although nicotine is recognized to evoke an inflammatory response in macrophages, there is no direct evidence to demonstrate the pro-inflammatory effect of nicotine on macrophages through CRP. Therefore, the pre-

\footnotetext{
${ }^{1}$ Department of Pharmacology, Xi'an Jiaotong University School of Medicine, Xi'an, P.R. China, ${ }^{2}$ Department of Pharmacy, the Affiliated Hospital of Xi'an Medical College, Xi'an, P.R. China, ${ }^{3}$ Department of Pharmacy, Lianyungang Hospital of Traditional Chinese Medicine, Lianyungang, China, ${ }^{4}$ Department of Pharmacology, Shaanxi Institute for Food and Drug Control, Xi'an, P.R. China
}

* Correspondence: lit@ @mail.xjtu.edu.cn 
A
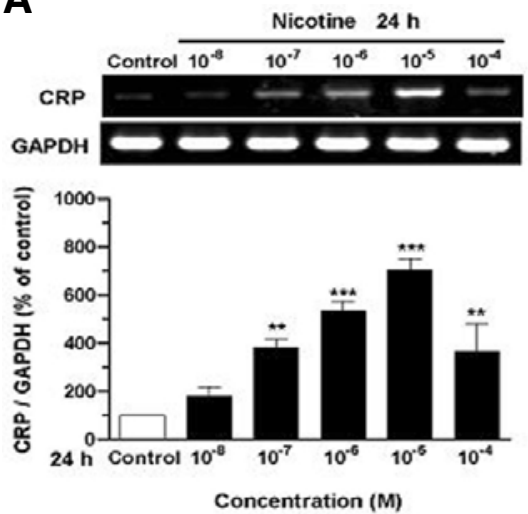

C
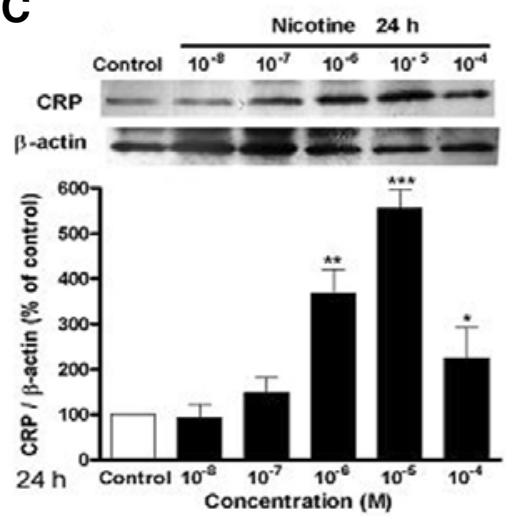

B

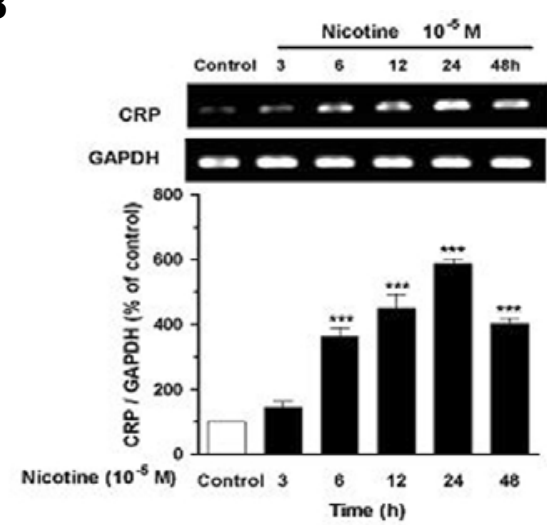

D

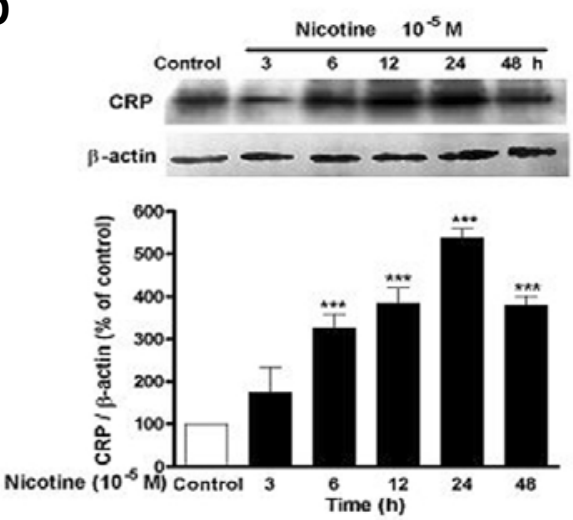

Fig. 1. Nicotine stimulates CRP generation in U937 macrophages. (A) Concentration dependence of CRP mRNA expression, (B) time dependence of CRP mRNA expression, (C) concentration dependence of CRP protein expression, and (D) time dependence of CRP protein expression in U937 macrophages. The cells were incubated with the different concentrations of nicotine for $24 \mathrm{~h}$ or with nicotine $\left(10^{-5} \mathrm{M}\right)$ for the indicated time. Then, mRNA level and protein expression of CRP were identified by RT-PCR and Western blot, respectively. Data from three independent experiments are expressed as means \pm S.E.M. ${ }^{\star} P<0.05,{ }^{\star \star} P<0.01$ and ${ }^{\star \star *} P<0.001$ vs. control. sent study was to observe effect of nicotine on CRP expression in U937 macrophages and the molecular mechanisms, particularly focusing on mitogen-activated protein kinases (MAPK)-NF$\kappa \mathrm{B}$ signal pathway.

\section{MATERIALS AND METHODS}

\section{Reagents}

Nicotine and hexamethonium used in this experiment were nicotine hydrogen tartrate salt and hexamethonium bromide, which were purchased from Sigma-Aldrich (USA). PD98059, SB203580, SP600125 and pyrrolidine dithiocarbamate (PDTC) were obtained from Sigma-Aldrich (USA). Rabbit polyclonal anti-human $\mathrm{C}$-reactive protein antibody was provided by Abcam (UK). Antibodies against phospho-ERK1/2, ERK1/2, phosphop38 MAPK and p38 MAPK were from the Beyotime Institute of Biotechnology (China).

\section{Cell culture}

U937 histiocytes (American Type Culture Collection) are also called resident macrophage. U937 macrophages were cultured in a $5 \% \mathrm{CO}_{2}$ atmosphere in RPMI-1640 supplemented with $10 \%$ fetal bovine serum (FBS) (Hyclone, USA), penicillin (100 $\mathrm{U} / \mathrm{ml})$ and streptomycin $(100 \mu \mathrm{g} / \mathrm{ml})$. The medium was changed every 1 or 2 days. When the cells were seeded into a 6-well plate at $1 \times 10^{6} \mathrm{cell} / \mathrm{s} / \mathrm{ml}$, the medium was changed to the serum free medium for an additional $12 \mathrm{~h}$ incubation to render the cells quiescent before adding the stimulus. In the experiments of inhibitors, U937 macrophages were exposed to nicotine $\left(10^{-5}\right.$ M) for $12 \mathrm{~h}$ after pretreated with the inhibitors for $1 \mathrm{~h}$.
Reverse transcription polymerase chain reaction (RT-PCR) Total RNA was isolated from U937 macrophages after the treatment using RNAfast200 (Fastagen, China) according to manufacturer's instruction. One microgram of isolated RNA from each sample was transcribed into complementary (cDNA) using oligo (dT) ${ }_{18}$ Primer and RevertAid ${ }^{\mathrm{TM}}$ M-MuLV Reverse Transcriptase (Fermentas, Germany). The cDNA was amplified using $2 \mu \mathrm{l}$ of each of the CRP forward primer $\left(5^{\prime}-\mathrm{TCG}\right.$ TGG AGT TCT GGG TAG ATG-3') and reverse primer (5'-TTC GCC TTG CAC TTC ATA CTT-3'). This resulted in a 275 bp PCR product ( 35 amplification cycles of $94^{\circ} \mathrm{C}$ for $5 \mathrm{~min}, 94^{\circ} \mathrm{C}$ for $30 \mathrm{~s}$, $61^{\circ} \mathrm{C}$ for $30 \mathrm{~s}, 72^{\circ} \mathrm{C}$ for $1 \mathrm{~min}$, and $72^{\circ} \mathrm{C}$ for $5 \mathrm{~min}$ ). The housekeeping gene (GAPDH) was amplified as an internal control for normalization using the forward primer (5'-GGA TTT GGT CGT ATT GGG-3') and the reverse primer (5'-GGA AGA TGG TGA TGG GAT T- $3^{\prime}$ ). This resulted in a 205 bp product (35 amplification cycles of $94^{\circ} \mathrm{C}$ for $5 \mathrm{~min}, 94^{\circ} \mathrm{C}$ for $30 \mathrm{~s}, 55^{\circ} \mathrm{C}$ for $30 \mathrm{~s}$, $72^{\circ} \mathrm{C}$ for $1 \mathrm{~min}$, and $72^{\circ} \mathrm{C}$ for $5 \mathrm{~min}$ ). PCR products were separated on $2 \%$ agarose gels. Results were expressed as relative to control.

\section{Western blotting}

The treated cells were washed with PBS, lysed by $200 \mu$ of icecold RIPA lysis buffer supplemented with the protease inhibitor cocktail (Roche, Germany). Protein concentration was measured by BCA protein assay kit (Pierce, USA). Equal amount of protein extract $(50 \mu \mathrm{g})$ was loaded, separated by $10 \%$ SDSPAGE, and blotted onto nitrocellulose membrane. Then, the membranes were incubated with rabbit polyclonal anti-CRP (1:100 dilution), anti-phospho-ERK (1:1,000 dilution), anti-ERK (1:1,000 dilution), anti-phospho-p38 MAPK (1:1,000 dilution), 
A
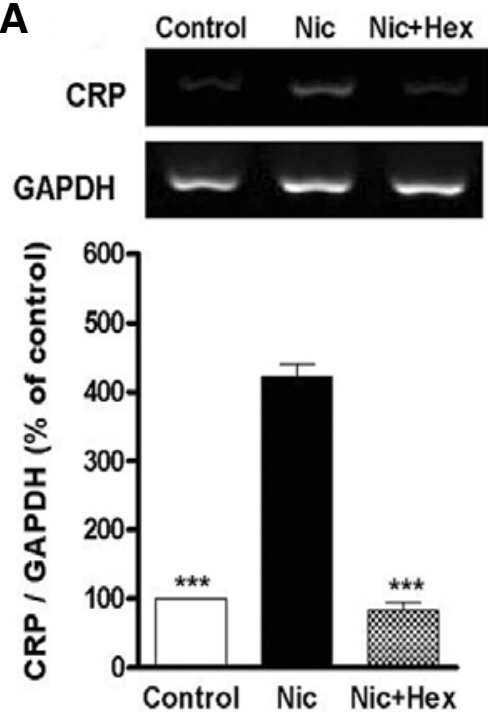

A

CRP
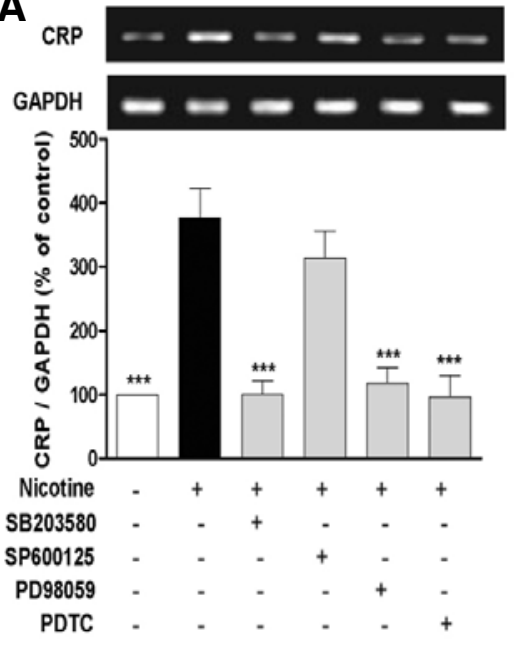

B
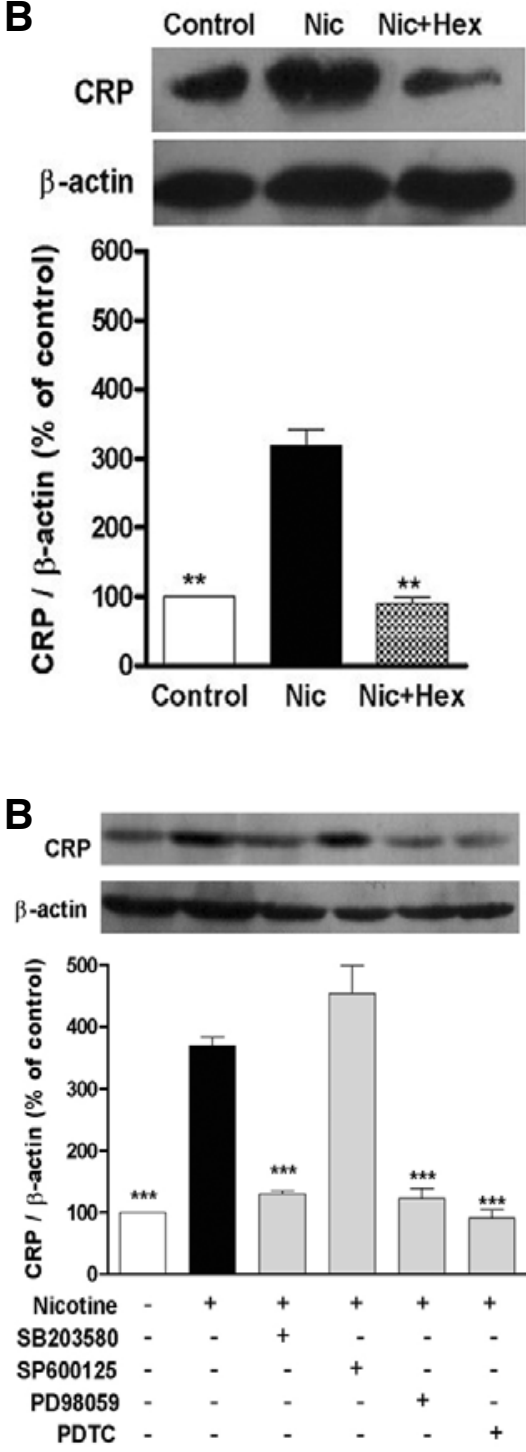

Fig. 2. Nicotine induces CRP expression in U937 macrophages via nAChR. The cells were pretreated with $\mathrm{nAChR}$ antagonist hexamethonium (Hex, $10^{-5} \mathrm{M}$ ) for $1 \mathrm{~h}$ prior to stimulation with nicotine $\left(10^{-5} \mathrm{M}, \mathrm{Nic}\right)$ for $12 \mathrm{~h}$. Then, mRNA level $(A)$ and protein expression (B) of CRP were analyzed by RT-PCR and Western blot, respectively. Data from three independent experiments are expressed as means \pm S.E.M. ${ }^{\star \star} P<0.01$ and ${ }^{* \star *} P<0.001$ vs. nicotine alone.
Fig. 3. MAPK and NF-kB mediate nicotineinduced expression of CRP in U937 macrophages. The cells were pretreated with PD98059 (MEK1/2 inhibitor, $20 \mu \mathrm{M}$ ), SP600125 (JNK inhibitor, $20 \mu \mathrm{M}$ ), SB203580 (p38 MAPK inhibitor, $10 \mu \mathrm{M}$ ) or PDTC (NF-kB inhibitor, $100 \mu \mathrm{M})$ for $1 \mathrm{~h}$ prior to stimulation with nicotine $\left(10^{-5} \mathrm{M}\right)$ for $12 \mathrm{~h}$. Then, mRNA level $(\mathrm{A})$ and protein expression (B) of CRP were detected by RT-PCR and Western blot, respectively. Data from three independent experiments are expressed as the mean \pm S.E.M. ${ }^{* \star} P<0.001$ vs. nicotine alone. and anti-p38 MAPK (1:1,000 dilution), anti-beta actin (1:1,000 dilution) antibodies overnight at $4^{\circ} \mathrm{C}$. After washed, the membranes were incubated with anti-rabbit or anti-mouse lgG antibody conjugated with horseradish peroxidase for $2 \mathrm{~h}$ at room temperature. The immunostaining was visualized by the enhanced chemiluminescence (Pierce, USA).

\section{Statistical analysis}

All values were shown as mean \pm S.E.M. Statistical significance between groups was assessed by one-way ANOVA, followed by Dunnett's multiple comparison tests. A value of $P<0.05$ was considered statistically significant.

\section{RESULTS}

Nicotine induces CRP expression in U937 macrophages Figures $1 \mathrm{~A}$ and $1 \mathrm{C}$ showed that nicotine at $10^{-8}-10^{-5} \mathrm{M}$ evidently up-regulated mRNA and protein expression of CRP in U937 macrophages in a concentration-dependent manner in comparison with control. The maximal response of 7.4 and 5.4 folds over control was reached at a concentration of $10^{-5} \mathrm{M}$. The results in Figs. 1B and 1D showed that nicotine also increased mRNA and protein expression of CRP in U937 macrophages in a time-dependent fashion. CRP expression was gradually increased, and reached the maximum $24 \mathrm{~h}$ after nicotine stimulation.

\section{Nicotine induces CRP expression in U937 macrophages via nAChR}

To test the role of $\mathrm{nAChR}$ in nicotine-induced CRP expression in U937 macrophages, the cells were pretreated with nAChR blockers hexamethonium for $1 \mathrm{~h}$ before nicotine stimulation. The results showed that hexamethonium abolished nicotineinduced mRNA and protein expression of CRP in U937 macrophages (Figs. 2A and 2B).

\section{Nicotine induces CRP expression in U937 macrophages} through nAChR-MAPK signal pathway

Following stimulation of U937 macrophages with $10^{-5} \mathrm{M}$ nicotine for $12 \mathrm{~h}, \mathrm{mRNA}$ and protein expression of CRP was signify- 
A

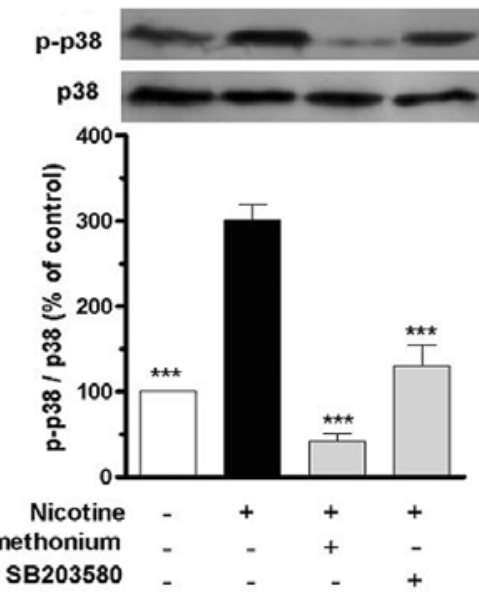

B

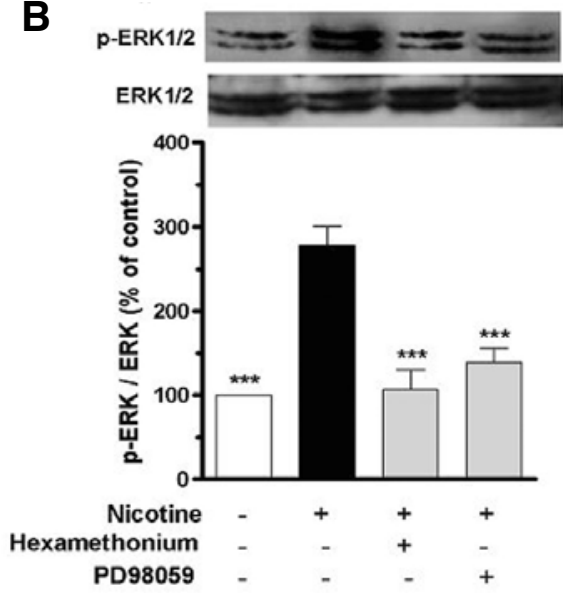

Fig. 4. Nicotine induces CRP expression in U937 macrophages through nAChRMAPK signal pathway. The cells were stimulated with nicotine $\left(10^{-5} \mathrm{M}\right)$ for $1 \mathrm{~h}$ after pretreated with hexamethonium $\left(10^{-5} \mathrm{M}\right)$, SB203580 (p38 MAPK inhibitor, $10 \mu \mathrm{M}$ ) or PD098059 (MEK1/2 inhibitor, $20 \mu \mathrm{M}$ ) for $1 \mathrm{~h}$. Then, expressions of ERK1/2 and p38 MAPK, phosphorylated ERK $1 / 2$ and p38 MAPK were measured by Western blot. Data from three independent experiments are expressed as the mean \pm S.E.M. ${ }^{\star \star \star} P<$ 0.001 vs. nicotine alone. cantly increased. However, pretreatment of the cells with PD98059 (MEK1/2 inhibitor), SB203580 (p38 MAPK inhibitor) or PDTC (NF-kB inhibitor) for $1 \mathrm{~h}$ almost completely antagonized nicotine-induced CRP expression. But, JNK inhibitor SP600125 did not show the similar effect (Figs. 3A and 3B).

The above-mentioned results indicate that nAChR, p38 MAPK and ERK1/2 participate in nicotine-induced CRP expression in U937 macrophages. To elucidate whether nAChR mediated nicotine-induced activation of p38 MAPK and ERK1/2 in U937 macrophages, the phosphorylated p38 MAPK and ERK1/2 were determined. Western blot analysis revealed that a marked increase of the phosphorylated p38 MAPK and ERK1/2 was detected following stimulation of the cells with nicotine. However, pretreatment of the cells with hexamethonium and PD98059 or SB203580 for $1 \mathrm{~h}$ prior to exposure of the cells to nicotine markedly inhibited nicotine-induced phosphorylation of p38 MAPK and ERK1/2 (Figs. 4A and 4B).

\section{DISCUSSION}

Epidemiological evidence demonstrates that cigarette smoking increases the incidence of cardiovascular diseases. Even though nicotine has been widely accepted as a risk factor for atherosclerosis (Ambrose and Barua, 2004), it is not completely known how nicotine contributes to atherosclerosis. Some investigators have provided evidence that nicotine promotes inflammation (Furie et al., 2000; Tottiet et al., 1984). By contrast, other studies indicate that nicotine produces an immunosuppressive effect in relatively high doses (Matsunaga et al., 2001).

Early studies demonstrated that nicotine induces production of various inflammatory mediators which are known to be an initial event of atherosclerotic pathogenesis (Lau et al., 2006; Wang et al., 2004). As the main inflammatory cells, monocytes and monocyte-derived macrophages have been recognized as the cellular hallmark of atherosclerosis (Rogacev et al., 2010). Monocytes are recruited to the vascular wall during the process of atherogenesis where they differentiate into macrophages and acquire the capacity to synthesize an array of cytokines, chemokines and growth factors, which contribute to the development of atherosclerosis (Wang et al., 2008).

As a representative marker of the inflammatory response, CRP participates in all stages of atherosclerotic process, and provides a pivotal link between inflammation and atherogenesis (Kaperonis et al., 2006). Although the elevated serum level of
CRP is predominately produced by hepatocytes, other types of cells such as VSMCs, vascular endothelial cells (VECs) and macrophages may secrete CRP (Ciubotaru et al., 2005; Han et al., 2010; Peng et al., 2007). Moreover, the locally produced CRP in the vessel wall may play a direct and essential role in the whole inflammatory process of atherosclerosis and the development of cardiovascular complications. The present results showed that nicotine stimulated mRNA and protein expression of CRP in U937 macrophages. The nicotine concentrations used in the experiment were $10^{-8}-10^{-4} \mathrm{M}$, which were approximately in accordance with the plasma levels of smokers $\left(10^{-8}\right.$. $\left.10^{-5} \mathrm{M}\right)$ (Benowitz, 1996). Therefore, the results demonstrate that nicotine produces a pro-inflammatory effect through stimulating CRP expression in U937 macrophages.

$\mathrm{nAChR}$ is widely distributed throughout the nervous system and other non-neuronal cells such as monocytes, endothelial cells, and epithelial cells (Conti-Fine et al., 2000; Davies et al., 1982; Macklin et al., 1998; Wang et al., 2001). Nicotine may activate nAChR. Therefore, nAChR possibly mediates the proinflammatory effect of nicotine on macrophages. In the present experiment, pretreatment of U937 macrophages with hexamethonium (a non-selective nAChR blocker) almost completely abolished nicotine-induced CRP increase in mRNA and protein levels, suggesting that nicotine induces CRP expression in macrophages via $\mathrm{nAChR}$.

A great number of investigations document that the MAPK family members (p38 MAPK, JNK and ERK) are important in regulating the production of inflammatory cytokines and mediators (Sun et al., 2008). In this study, we found that MEK $1 / 2$ inhibitor PD98059 and p38 MAPK inhibitor SB203580 substantially reduced nicotine-induced $\mathrm{mRNA}$ and protein expression of CRP in U937 macrophages, while JNK inhibitor SP600125 had no significant effect on CRP expression, implicating that nicotine-induced CRP expression in U937 macrophages depends on ERK $1 / 2$ and p38 MAPK signaling. This finding is consistent with our previous results that angiotensin II induces CRP expression through ERK1/2 and p38 MAPK signal pathway in U937 macrophages (Li et al., 2011). In addition, we also found that nAChR antagonist hexamethonium inhibited nicotineinduced phosphorylation of ERK1/2 and p38 MAPK in U937 macrophages, certifying that nicotine activates phosphorylation of ERK $1 / 2$ and p38 MAPK through nAChR, and ERK1/2 and p38 MAPK are the downstream molecules of $n A C h R$.

As a major transcription factor in inflammatory response, NF- 
$\kappa B$ is considered to be a downstream molecule of MAPK. Nicotine is able to promote NF- $\mathrm{KB}$ activation in macrophages and VECs (Lau et al., 2006; Zhou et al., 2010). Our result exhibited that NF- $\mathrm{KB}$ was involved in nicotine-induced CRP expression in U937 macrophages, since the selective NF-kB inhibitor PDTC completely blocked CRP expression in response to nicotine.

In summary, these data demonstrate that nicotine induces CRP expression in macrophages via nAChR-ERK1/2/p38 MAPK-NF-KB signal pathway, which contributes to better understanding of the pro-inflammatory and pro-atherosclerotic effects of nicotine in cigarette smokers.

\section{ACKNOWLEDGMENTS}

This work was supported by the Doctoral Fund of the Ministry of Education of China (No. 20100201110053).

\section{REFERENCES}

Ambrose, J.A., and Barua, R.S. (2004). The pathophysiology of cigarette smoking and cardiovascular disease: an update. J. Am. Coll Cardiol. 43, 1731-1737.

Benowitz, N.L. (1996). Pharmacology of nicotine: addiction and therapeutics. Annu. Rev. Pharmacol. Toxicol. 36, 597-613.

Ciubotaru, I., Potempa, L.A., and Wander, R.C. (2005). Production of modified C-reactive protein in U937-derived macrophages. Exp. Biol. Med. (Maywood) 230, 762-770.

Conti-Fine, B.M., Navaneetham, D., Lei, S., and Maus, A.D.J. (2000). Neuronal nicotinic receptors in non-neuronal cells: new mediators of tobacco toxicity? Eur. J. Pharmacol. 393, 279-294.

Davies, B.D., Hoss, W., Lin, J.P., and Lionetti, F. (1982). Evidence for a noncholinergic nicotine receptor on human phagocytic leukocytes. Mol. Cell. Biochem. 44, 23-31.

Denis, M., Cormier, Y., Tardif, J., Ghadirian, E., and Lariolette, M. (1991). Hypersensitivity pneumonitis-whole micropolyspora faeni or antigens thereof stimulate the release of proinflammatory cytokines from macrophages. Am. J. Respir. Cell. Mol. Biol. 5, 198-203.

Diaz, P.D., Bleeker, W.K., Lubbers, Y., Rigter, G.M., Van Mierlo, G.J., Daha, M.R., and Hack, C.E. (2003). Rat C-reactive protein activates the autologous complement system. Immunology 109, 564-571.

Furie, M.B., Raffanello, J.A., Gergel, E.I., Lisinski, T.J., and Horb, L.D. (2000). Extracts of smokeless tobacco induce pro-inflammatory changes in cultured human vascular endothelial cells. Immunopharmacology 47, 13-23.

Han, C.J., Liu, J.T., Liu, X.F., and Li, M. (2010). Angiotensin II induces C-reactive protein expression through ERK $1 / 2$ and JNK signaling in human aortic endothelial cells. Atherosclerosis 212, 206-212.

Hansson, G.K., and Hermansson, A. (2011). The immune system in atherosclerosis. Nat. Immunol. 12, 204-212.

Haraldsen, G., Kvale, D., Lien, B., Farstad, I.N., and Brandtzaeg, P. (1996). Cytokines-regulated expression of E-selectin, intercellular adhesion molecule-1 (ICAM-1), and vascular cell adhesion molecular-1 (VCAM-1) in human interstinal microvascular endothelial cells. J. Immunol. 156, 2558-2565.

Kaperonis, E.A., Liapis, C.D., Kakisis, J.D., Dimitroulis, D., and Papavassiliou, V.G. (2006). Inflammation and atherosclerosis. Eur. J. Vasc. Endovasc. Surg. 31, 386-393.

Kibayashi, E., Urakaze, M., Kobashi, C., Kishida, M., Takata, M., Sato, A., Yamazaki, K., and Kobayashi, M. (2005). Inhibitory effect of pitavastatin (NK-104) on the C-reactive protein-induced interleukin-8 production in human aortic endothelial cells. Clin. Sci. 108, 515-521.

Lau, P.P., Li, L., Merched, A.J., Zhang, A.L., Ko, K.W.S., and Chan, L. (2006). Nicotine induces proinflammatory responses in macrophages and the aorta leading to acceleration of atherosclerosis in low-density lipoprotein receptor (-/-) mice. Arterioscler. Thromb. Vasc. Biol. 26, 143-149.

Lee, J., and Cooke, J.P. (2011). The role of nicotine in the pathogenesis of atherosclerosis. Atherosclerosis 215, 281-283.

Li, L., Roumeliotis, N., Sawamura, T., and Renier, G. (2004). Creactive protein enhances LOX-1 expression in human aortic endothelial cells: relevance of LOX-1 to C-reactive proteininduced endothelial dysfunction. Circ. Res. 95, 877-883.

Li, M., Liu, J.T., Han, C.J., Wang, B., Pang, X.M., and Mao, J.J. (2011). Angiotensin II induces the expression of C-reactive protein via MAPK-dependent signal pathway in U937 macrophages. Cell. Physiol. Biochem. 27, 63-70.

Macklin, K.D., Maus, A.D.J., Pereira, E.F.R., Albuquerque, E.X., and Conti-Fine, B.M. (1998). Human vascular endothelial cells express functional nicotinic acetylcholine receptors. J. Pharmacol. Exp. Ther. 287, 435-439.

Matsunaga, K., Klein, T.W., Friedman, H., and Yamamoto, Y. (2001). Involvement of nicotinic acetylcholine receptors in suppression of antimicrobial activity and cytokine responses of alveolar macrophages to Legionella pneumophila infection by nicotine. J. Immunol. 167, 6518-6524.

Morzycki, W., Sadowska, J., and Issekutz, A.C. (1990). Interleukin-1 and tumor necrosis factor $\alpha$ induced polymorphonuclear leukocyte- endothelial cell adhesion and transendothelial migration in vitro: The effects of apical versus basal monolayer stimulation Immunol. Lett. 25, 33-40.

Michael. P.R. (2000). Cigarette smoking, endothelial injury and cardiovascular disease. Int. J. Exp. Pathol. 81, 219-230.

Peng, N., Liu, J.T., Gao, D.F., Lin, R., and Li, R. (2007). Angiotensin II-induced C-reactive protein generation: Inflammatory role of vascular smooth muscle cells in atherosclerosis. Atherosclerosis 193, 292-298.

Ridker, P.M. (2003). Clinical application of C-reactive protein for cardiovascular disease detection and prevention. Circulation 107, 363-369.

Rogacev, K.S., Ulrich, C., Blomer, L., Hornof, F., Oster, K., Ziegelin, M., Cremers, B., Grenner, Y., Geisel, J., Schlitt, A., et al. (2010). Monocyte heterogeneity in obesity and subclinical atherosclerosis. Eur. Heart J. 31, 369-376.

Sun, J., Ramnath, R.D., Zhi, L., Tamizhselvi, R., and Bhatia, M. (2008). Substance P enhances NF-kappa B transactivation and chemokine response in murine macrophages via ERK1/2 and p38 MAPK signaling pathways. Am. J. Physiol. Cell. Physiol. 294, C1586-C1596.

Totti, N., McCusker, K.T., Campbell, E.J., Griffin, G.L., and Senior, R.M. (1984). Nicotine is chemotactic for neutrophils and enhances neutrophil responsiveness to chemotactic peptides. Science 223, 169-171.

Tsiara, S., Elisaf, M., and Mikhailidis, D.P. (2003). Influence of smoking on predictors of vascular disease. Angiology 54, 507-530.

Venugopal, S.K., Devaraj, S., Yuhanna, I., Shaul, P., and Jialal, I. (2002). Demonstration that C-reactive protein decreases eNOS expression and bioactivity in human aortic endothelial cells, Circulation 106, 1439-1441.

Venugopal, S.K., Devaraj, S., and Jialal, I. (2003). C-reactive protein decreases prostacyclin release from human aortic endothelial cells. Circulation 108, 1676-1678.

Wang, Y., Pereira, E.F., Maus, A.D., Ostlie, N.S., Navaneetham, D., Lei, S., Albuquerque, E.X., and Conti-Fine, B.M. (2001). Human bronchial epithelial and endothelial cells express alpha7 nicotinic acetylcholine receptors. Mol. Pharmacol. 60, 1201-1209.

Wang, Y.J., Wang, L.Y., Ai, X.J., Zhao, H.L., Hao, X.F., Lu, Y.T. and Qiao, Z.D. (2004). Nicotine could augment adhesion molecule expression in human endothelial cells through macrophages secreting TNF- $\alpha$, IL-1 $\beta$. Int. Immunopharmacol. 4, 16751686 .

Wang, W.L., Haller, C.A., Wen, J., Wang, P.Y., and Chaikof, E.L. (2008). Decoupled syndecan $1 \mathrm{mRNA}$ and protein expression is differentially regulated by angiotensin II in macrophages. J. Cell. Physiol. 214, 750-756.

Yoshiyama, S., Horinouchi, T., Miwa, S., Wang, H.H., Kohama, K., and Nakamura, A. (2011). Effect of cigarette smoke components on vascular smooth muscle cell migration toward plateletderived growth factor BB. J. Pharmacol. Sci. 115, 532-535.

Zhou, Y., Wang, Z.X., Tang, M.P., Yao, C.J., Xu, W.J., Wang, L.Y. and Qiao, Z.D. (2010). Nicotine induces cyclooxygenase-2 and prostaglandin $E_{2}$ expression in human umbilical vein endothelial cells. Int. Immunopharmacol. 10, 461-466.

Zwaka, T.P., Hombach, V., and Torzewski, J. (2001). C-reactive protein-mediated low density lipoprotein uptake by macrophages Implications for atherosclerosis. Circulation 103, 1194-1197. 
